\title{
Orosomucoid Content of Pleural and Peritoneal Effusions
}

\author{
Daniel Rudman, Rajender K. Chawla, Alejandro E. Del Rio, \\ Bettye M. Holuins, Elmer C. Hall, and Judy M. Conn \\ From the Departments of Medicine, Biochemistry, and Biometry, Emory \\ University School of Medicine and the Clinical Research Facility, Emory \\ University Hospital, Atlanta, Georgia 30322
}

A в S T R A C T 22 nonneoplastic, noninflammatory effusions (cirrhosis and congestive heart failure), 12 nonneoplastic inflammatory effusions (tuberculosis, lupus erythematosus, rheumatoid arthritis, and idiopathic pleuropericarditis), and 58 neoplastic effusions (cancer of lung, breast, ovary, and pancreas, and lymphoma) were analyzed by radial immunodiffusion for orosomucoid concentration. The average concentration $\pm \mathrm{SE}$ was $35 \pm 4,65 \pm 17$, and $130 \pm 13 \mathrm{mg} / 100 \mathrm{ml}$ in the three types of effusion, respectively. By gel filtration and ion exchange chromatography, orosomucoid was isolated from 12 nonmalignant and 14 malignant fluids. The orosomucoid preparations reacted as single components in acrylamide gel electrophoresis at $\mathrm{pH}$ 9.0, and in immunodiffusion and immunoelectrophoresis against antisera to human serum and to human plasma orosomucoid. In radial immunodiffusion, the slope of the line relating concentration to the square of the diameter of the precipitate area was identical for orosomucoid isolated from normal human plasma and from nonneoplastic effusions, but was subnormal for orosomucoid isolated from neoplastic fluids. All orosomucoid preparations had normal amino acid composition. Orosomucoid from the nonmalignant effusions had normal carbohydrate content. 11 of 14 samples of orosomucoid isolated from neoplastic fluids had abnormalities in carbohydrate composition, consisting of subnormal content of sialic acid (11 of 14), hexose (10 of 14), and hexosamine (3 of 14 ), and abnormally high content of hexosamine (4 of 14).

Discriminant analysis showed that concentration of orosomucoid distinguished between neoplastic and nonneoplastic noninflammatory effusions more effectively than concentration of total protein, albumin, $\alpha_{1}, \alpha_{2}, \beta$, or $\gamma$-globulin.

Received for publication 12 September 1973 and in revised form 8 January 1974.

\section{INTRODUCTION}

Patients with neoplastic disease frequently have elevated concentration of orosomucoid ( $\alpha_{1}$ acid glycoprotein) in plasma (1). We recently developed a method for isolating homogeneous orosomucoid from as little as $3 \mathrm{ml}$ plasma and found that the circulating orosomucoid in patients with advanced cancer usually possesses an abnormal carbohydrate composition (2).

The present study investigated concentration and composition of orosomucoid in effusions of neoplastic and nonneoplastic etiology.

\section{METHODS}

57 pleural and 35 peritoneal effusions were studied; etiology was neoplastic in 58 (Table I). The fluids were anticoagulated by heparin, centrifuged to remove red blood cells, and stored at $-20^{\circ} \mathrm{C}$ within $1 \mathrm{~h}$ after paracentesis.

In all cancer cases, histologic diagnosis and metastatic involvement of visceral or parietal pleura or peritoneum were demonstrated at autopsy. Diagnosis of Laennec's cirrhosis was confirmed by needle biopsy or autopsy.

Each effusion was analyzed for total protein concentration (3) and protein electrophoretic pattern (4). In addition, $1 \mathrm{ml}$ of each effusion was examined by gel filtration in $1 \mathrm{~N}$ acetic acid on a $2 \times 200-\mathrm{cm}$ column of Sephadex G-75 (5). Protein content of the effluent was monitored by measuring optical density at $280 \mathrm{~nm}$. Proteins were recovered from effluent by lyophilization.

Homogeneous normal human plasma orosomucoid was prepared by purification of commercial human plasma fraction VI (Schwarz/Mann Div., Becton, Dickinson \& Co., Orangeburg, N. Y.) as described elsewhere (2). Orosomucoid was isolated from effusions by the method previously developed for plasma (2). To characterize orosomucoid preparations, the following tests were done (2): acrylamide gel electrophoresis at $\mathrm{pH} 9.0$; measurements of amino acid and carbohydrate compositions; immunodiffusion (at $\mathrm{pH}$ 7.2) and immunoelectrophoresis (at $\mathrm{pH}$ 8.6) against these antisera (Hyland Div., Travenol Laboratories, Inc., Costa Mesa, Calif., and Behringwerke AG, Marburg-Lahn, W. Germany) : rabbit antisera to whole human serum, orosomucoid, $\alpha$-lipoprotein, transferrin, $\alpha_{2}$-haptoglobin, fibrinogen, albumin, $\gamma \mathrm{G}$-immunoglobulin, $\beta_{1} \mathrm{C} / \beta_{1}$ A-globulin, $\alpha_{1}$-antitrypsin, $\alpha$-fetoprotein, $\alpha_{2}$ HS glycoprotein, hemopexin, and 
TABLE I

Protein Analyses

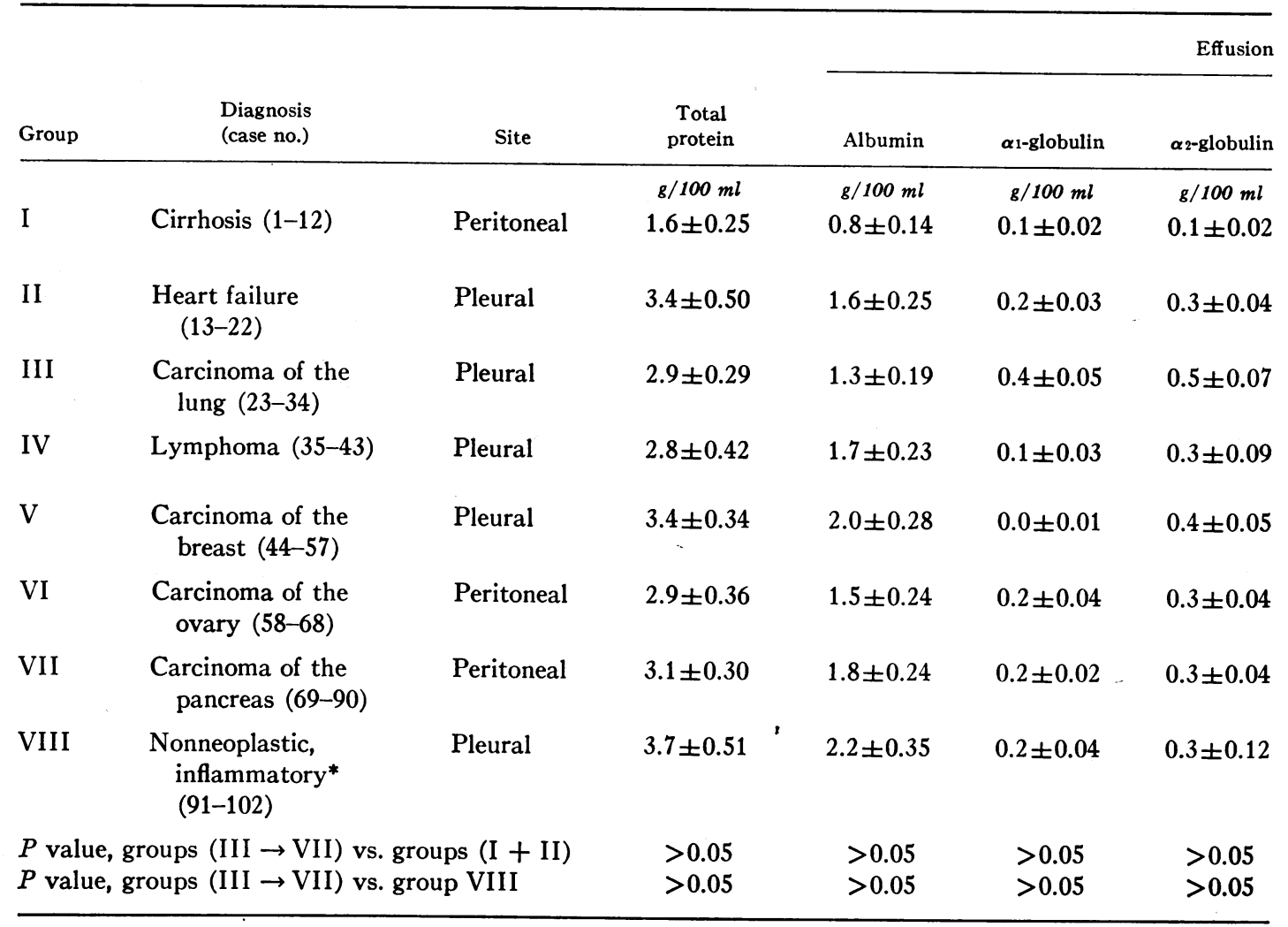

* Tuberculosis, five; lupus erythematosus, three; rheumatoid arthritis, two; idiopathic pleuropericarditis, two. Values represent av \pm SE. Number of observations is same as number of cases for effusion data; number of plasmas analyzed is indicated in parentheses after total protein value.

$\beta_{2} \mathrm{C}$ glycoprotein; horse antisera to $\beta$-lipoprotein and $\mathrm{Gc}$ globulins; goat antiserum to $\alpha_{2}$-macroglobulin. Rabbit antiserum to orosomucoid with subnormal carbohydrate content, isolated from plasma of patient 19 (ref. 2) with acute myelocytic leukemia, was also employed.

Effusions were assayed for content of orosomucoid by radial immunodiffusion (6) in immunoplates obtained from Behringwerke.

In $45 \%$ of patients, plasma obtained within 2 days of paracentesis was analyzed for concentrations of protein (3) and orosomucoid (6).

\section{RESULTS}

Gel filtration chromatography. The elution profile of normal serum (Fig. 1) shows three elevations. These peaks, labeled $a, b$, and $c$, are identified by their distribution coefficient, $K_{d d^{1}}$ The cube root of $K_{d}$ is, approximately, a linear function of square root of the protein's mol wt (7). $a$ is a major protein peak at $K_{d} 0-0.1$, approximate mol wt 69,000 , representing albumin and most plasma globulins. $b$ is a minor protein peak at $K_{d} 0.2-$

\footnotetext{
${ }^{1} K d=\left(V_{0}-V_{0}\right) / V_{i}$, where $V_{0}$ is elution volume of the test substance, $V_{0}$ is void volume, and $V_{t}$ is solvent imbibed by the gel ( 7$)$.
}

0.3 , mol wt $45,000-69,000$, representing at least 12 proteins ${ }^{2}$ of plasma in this mol wt range. $c$ is a prominent peak at $K_{d}=1.0$, representing tryptophan, tyrosine, and other substances with mol wt $<3,000$ that absorb light at $280 \mathrm{~nm}$.

The elution profile of 22 nonmalignant effusions (12 cirrhotic, 10 congestive heart failure) resembled the normal serum pattern (Fig. 1A and 1B). In contrast, most neoplastic effusions showed enlargement of peak $b$ (Fig. 1C). This peak was recovered by lyophilization, repurified twice by gel filtration on Sephadex G75, and analyzed for content of orosomucoid by radial immunodiffusion. Yield of peak $b$ was 10 times greater in neoplastic (av $530 \mathrm{mg} / 100 \mathrm{ml}$ ) than in benign effusions (av $58 \mathrm{mg} / 100 \mathrm{ml}$ ); about $20 \%$ of this difference was accounted for by increased content of orosomucoid.

Measurement of orosomucoid in the effusions was done by the radial immunodiffusion technique (Table

Prealbumin, orosomucoid, $\alpha_{1}$-trypsin inhibitor, fetuin, M-2-glycoprotein, $\mathrm{Zn} \alpha_{2}$-glycoprotein, prothrombin, $\alpha_{1} 3.5 \mathrm{~S}$ glycoprotein, $\alpha_{1}$ easily precipitable glycoprotein, thyroxinebinding globulin, Gc globulin, and $\alpha_{2} \mathrm{HS}$ glycoprotein. 
of 102 Effusions

\begin{tabular}{|c|c|c|c|c|c|c|}
\hline \multicolumn{4}{|l|}{ Effusion } & \multicolumn{3}{|c|}{ Plasma } \\
\hline \multirow[b]{2}{*}{$\beta$-globulin } & \multirow[b]{2}{*}{$\gamma$-globulin } & \multirow[b]{2}{*}{ Orosomucoid } & \multirow{2}{*}{$\frac{\text { Orosomucoid }}{\text { Total protein }}$} & \multirow{2}{*}{$\begin{array}{c}\text { Total } \\
\text { protein }\end{array}$} & \multirow[b]{2}{*}{ Orosomucoid } & \multirow{2}{*}{$\frac{\text { Orosomucoid }}{\text { Total protein }}$} \\
\hline & & & & & & \\
\hline $\mathrm{g} / 100 \mathrm{ml}$ & $\mathrm{g} / 100 \mathrm{ml}$ & $\mathrm{mg} / 100 \mathrm{ml}$ & & $\mathrm{g} / 100 \mathrm{ml}$ & $\mathrm{mg} / 100 \mathrm{ml}$ & \\
\hline $0.2 \pm 0.05$ & $0.4 \pm 0.06$ & $27 \pm 3.2$ & $23 \pm 4.1$ & $\begin{array}{c}5.0 \pm 1.3 \\
(6)\end{array}$ & $78 \pm 5.1$ & $15 \pm 3.1$ \\
\hline $0.5 \pm 0.08$ & $0.8 \pm 0.19$ & $47 \pm 6.3$ & $17 \pm 2.9$ & $\begin{array}{c}7.0 \pm 1.4 \\
(5)\end{array}$ & $100 \pm 9.3$ & $14 \pm 3.0$ \\
\hline $0.3 \pm 0.02$ & $0.5 \pm 0.05$ & $133 \pm 14.7$ & $47 \pm 4.1$ & $\begin{array}{c}7.1 \pm 0.9 \\
(5)\end{array}$ & $158 \pm 16.4$ & $22 \pm 4.3$ \\
\hline $0.4 \pm 0.10$ & $0.3 \pm 0.07$ & $134 \pm 16.3$ & $66 \pm 22.9$ & $\begin{array}{c}7.3 \pm 1.0 \\
(5)\end{array}$ & $186 \pm 15.4$ & $25 \pm 5.0$ \\
\hline $0.5 \pm 0.05$ & $0.40 \pm 0.06$ & $129 \pm 13.1$ & $42 \pm 5.6$ & $\begin{array}{c}6.2 \pm 0.9 \\
(7)\end{array}$ & $165 \pm 18.7$ & $27 \pm 5.6$ \\
\hline $0.4 \pm 0.06$ & $0.5 \pm 0.13$ & $132 \pm 11.0$ & $49 \pm 4.6$ & $\begin{array}{c}6.7 \pm 1.4 \\
(5)\end{array}$ & $140 \pm 21.2$ & $21 \pm 4.4$ \\
\hline $0.4 \pm 0.04$ & $0.5 \pm 0.06$ & $111 \pm 12.8$ & $37 \pm 4.8$ & $\begin{array}{c}6.7 \pm 0.7 \\
(5)\end{array}$ & $159 \pm 18.7$ & $24 \pm 4.9$ \\
\hline $0.3 \pm 0.14$ & $0.7 \pm 0.10$ & $65 \pm 17.0$ & $18 \pm 6.3$ & & & \\
\hline$>0.05$ & $>0.05$ & $<0.01$ & $<0.02$ & $>0.05$ & $<0.05$ & $>0.05$ \\
\hline$>0.05$ & $>0.05$ & $<0.01$ & $<0.02$ & & & \\
\hline
\end{tabular}

I). Average orosomucoid concentration was 3.7 times higher in neoplastic than in nonneoplastic, noninflammatory effusions $(130 \mathrm{mg} / 100 \mathrm{ml} \pm 13$ [av $\pm \mathrm{SE}$ ] compared to $35 \pm 4$ ), and 2.0 times higher than in nonneoplastic, inflammatory fluids.

Isolation of orosomucoid from neoplastic and nonneoplastic effusions: differences in chemical composition. Orosomucoid was isolated from 12 nonneoplastic (8 noninflammatory, 4 inflammatory) and 14 neoplastic effusions by the previously described method (2). Immunodiffusion versus specific rabbit antisera showed that the orosomucoid preparations contained no albumin, $\alpha$-lipoprotein, transferrin, $\alpha_{2}$-haptoglobin, fibrinogen, $\gamma \mathrm{G}$ immunoglobulin, $\beta_{1} \mathrm{C} / \beta_{1}$ A-globulin, $\alpha_{1}$-antitrypsin, $\alpha$-fetoprotein, $\alpha_{2} \mathrm{HS}$ glycoprotein, hemopexin, $\beta_{2} \mathrm{C}$-glycoprotein, $\beta$-lipoprotein, $\mathrm{Gc}$ globulin, or $\alpha_{2}$-macroglobulin. The orosomucoid preparations moved as a single component in acrylamide gel electrophoresis at $\mathrm{pH} 9.0$ (Fig. 2 ) ; they reacted with a single line of precipitation in Ouchterlony immunodiffusion and in immunoelectrophoresis versus antiserum to normal orosomucoid and versus antiserum to normal human serum (Fig. 3).
The orosomucoids isolated from both neoplastic and nonneoplastic effusions were indistinguishable from normal human plasma orosomucoid in these electrophoretic and immunologic tests (Figs. 2 and 3). Likewise, in radial immunodiffusion, orosomucoids isolated from nonmalignant effusions and from normal plasma were indistinguishable (Fig. 4). Each of five neoplastic orosomucoids examined by this technique, however, showed a subnormal slope for the line relating concentration of the glycoprotein to square of diameter of the precipitate area (Fig. 4).

Orosomucoids derived from benign and malignant effusions were also tested in double immunodiffusion and immunoelectrophoresis against an antiserum to orosomucoid with subnormal carbohydrate content isolated from plasma of a patient with acute myelocytic leukemia (case 19, ref. 2). Results were indistinguishable from those with antiserum to normal human plasma orosomucoid (Fig. 3).

Yields of orosomucoid averaged 115, 28, and $45 \mathrm{mg}$ / $100 \mathrm{ml}$ for neoplastic, nonneoplastic noninflammatory, and nonneoplastic inflammatory effusions, respectively 

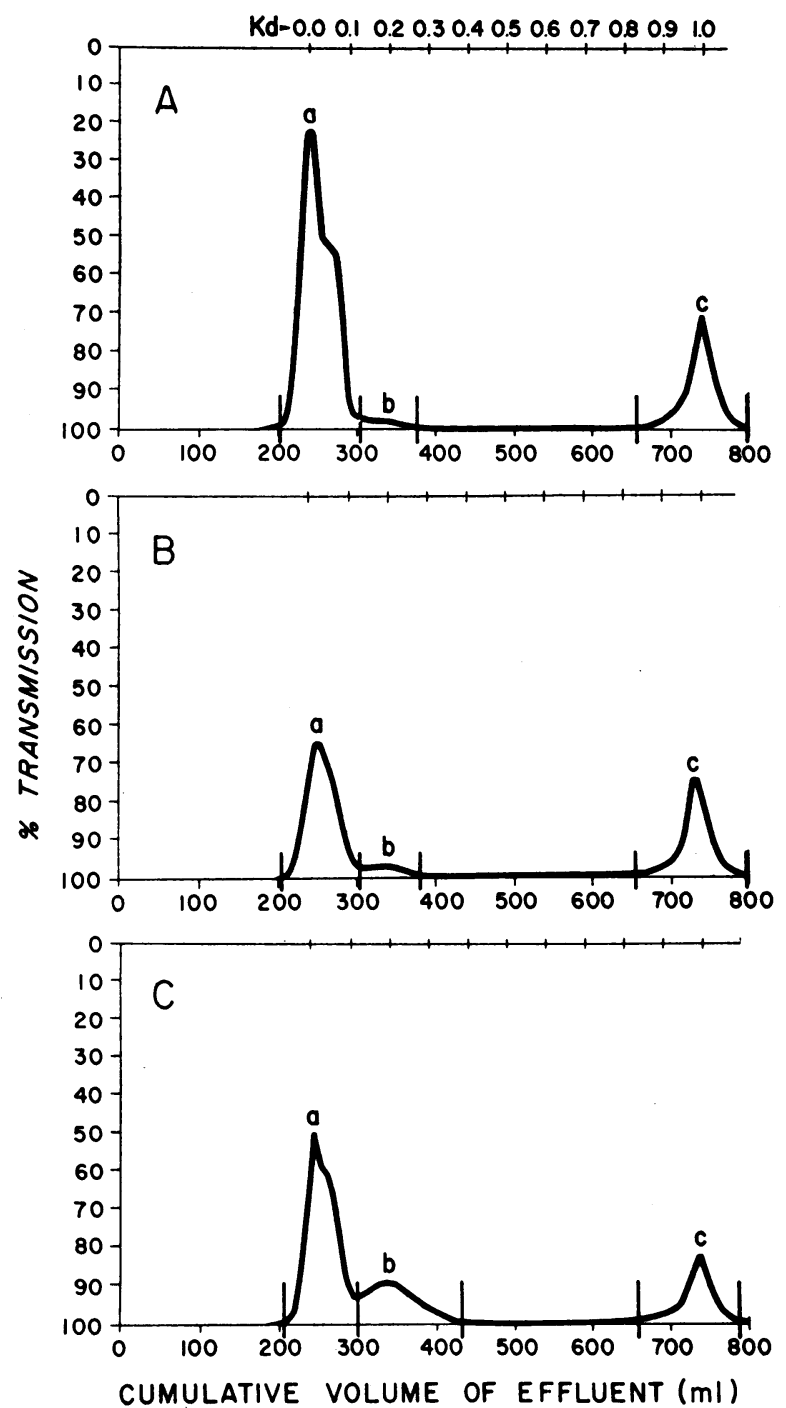

Figure 1 Elution profiles from gel-filtration on $2 \times 200-\mathrm{cm}$ column of Sephadex G75 in $1.0 \mathrm{~N}$ acetic acid. (A) $0.5 \mathrm{ml}$ normal human plasma. (B) $3 \mathrm{ml}$ peritoneal effusion from case 8 (Laennec's cirrhosis). (C) $3 \mathrm{ml}$ of peritoneal effusion from case 63 (carcinoma of the ovary).

(Table II). The amino acid compositions of all 26 preparations were indistinguishable ${ }^{3}$ from those of the normal plasma glycoprotein (2). The carbohydrate compositions of orosomucoid from benign. effusions were also closely similar to those of the normal material, but the compositions of the glycoprotein from 11 of the 14 neoplastic effusions showed differences ${ }^{3}$ in one or more of the carbohydrate moieties (Table II).

\footnotetext{
${ }^{3}$ An amino acid or carbohydrate content was considered "abnormal" if it differed from the average content of normal human plasma orosomucoid by $2 \mathrm{SD}$ or more.
}

\section{DISCUSSION}

The content of orosomucoid in nonneoplastic and neoplastic effusions can be compared in terms of either absolute concentration or the ratio of orosomucoid to total protein. In both respects, the content is two to five times greater in the malignant fluids (Table I).

Normally orosomucoid and other plasma glycoproteins are formed exclusively in the liver (8). In animals with neoplastic disease, however, a portion of the circulating glycoproteins may be synthesized by tumor (9). In cirrhosis and heart failure, the ratio orosomucoid/ total protein is generally similar in effusion and in plasma (Table I), as expected if the effusion's proteins are derived from plasma. In cancer patients, this ratio is 1.5-2.6 times higher in effusion than in corresponding plasma (Table I). This enrichment of the neoplastic effusion with orosomucoid could result if a portion of the effusion's glycoprotein were produced locally by tumor tissue within the involved synovial cavity.

Rovestad, Bartholemew, Cain, McKenzie, and Soule (10) and Spak (11) showed that concentrations of albumin, and $\alpha_{1}, \alpha_{2}$, and $\gamma$-globulins, and ratios $\left(\alpha_{1}+\alpha_{2}\right)$ globulin $/ \gamma$-globulin, and $\gamma$-globulin/total protein, tended to be higher in neoplastic than in nonneoplastic, noninflammatory effusions. The data of Table I suggest that concentration of orosomucoid in the effusion or the ratio of orosomucoid/total protein discriminates more effectively between neoplastic and nonneoplastic, noninflammatory effusions than do the indices proposed by

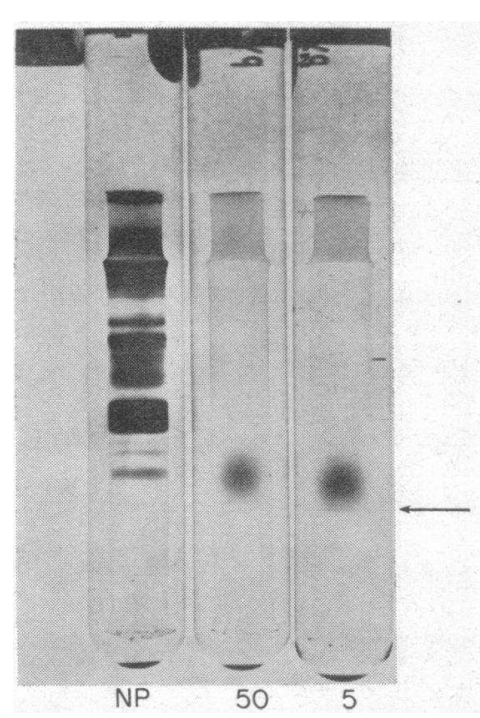

Figure 2 Acrylamide gel electrophoresis at $\mathrm{pH} 8.9$ of : normal human plasma (NP) ; orosomucoid isolated from pleural effusion of case 50 , carcinoma of breast; orosomucoid isolated from peritoneal effusion of case 5 , alcoholic cirrhosis. Arrow indicates tracking dye, bromphenol blue. 


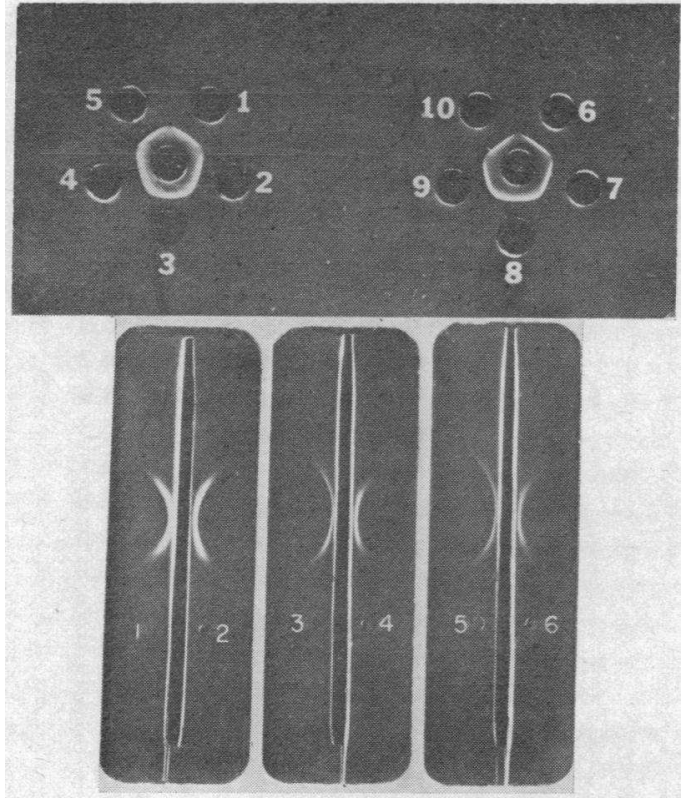

FIGURE 3 Immunologic tests with orosomucoid preparations. Above: Immunodiffusion. Center wells contained rabbit antiserum to normal human plasma orosomucoid. Peripheral wells contained orosomucoid derived from the following sources: 1 , normal human plasma; 2 , effusion caused by cirrhosis (case 3 ) ; 3 , effusion caused by congestive heart failure (case 17 ) ; 4, effusion caused by carcinoma of breast (case 50 ) ; 5 , effusion caused by carcinoma of lung (case 24); 6, normal human plasma; 7, effusion caused by cirrhosis (case 4 ) ; 8 , effusion caused by congestive heart failure (case 18); 9 , effusion caused by lymphoma (case 36 ) ; 10, effusion caused by carcinoma of pancreas (case 75). Below: Immunoelectrophoresis. Troughs contained rabbit antiserum to normal human plasma orosomucoid. Wells contained orosomucoid from following sources: 1, normal human plasma; 2 , effusion caused by cirrhosis (case 50); 3, normal human plasma; 4, effusion caused by carcinoma of the breast (case 50 ) ; 5 , effusion caused by carcinoma of pancreas (case 75 ); 6, effusion caused by carcinoma of lung (case 24 ).

Rovestad et al. (10) and Spak (11). Statistical analysis of this topic is provided in the Appendix.

Plasma orosomucoid is a mixture of five isomers with identical amino acid and carbohydrate compositions (12). The isomeric aspects of effusion orosomucoid were not studied. Orosomucoid isolated from benign effusions was normal in both amino acid and carbohydrate composition. The glycoprotein isolated from 14 malignant effusions also possessed a protein moiety with normal amino acid contents, but in 11 of the 14 preparations, the structure of the carbohydrate side chains was abnormal. The abnormality consisted of subnormal content of sialic acid (11 of 14), hexose (10 of 14), and hexosamine ( 3 of 14), or abnormally high content of hexosamine (4 of 14). The wide variations in ratios of the three types of carbohy- drate in neoplastic orosomucoid (Table II) suggest multiple abnormalities in the carbohydrate side chains, of which seven are normally present in each molecule of the glycoprotein (13). Qualitatively similar changes were previously observed (2) in the orosomucoid that accumulates in these patients' plasma, but the abnormalities in the effusion's glycoprotein tend to be greater. This tendency can be explained by assuming that orosomucoid in both plasma and effusion of patients with advanced neoplastic disease is a mixture of (a) normal glycoprotein produced by liver and $(b)$ abnormal glycoprotein produced by tumor, and that the ratio of $(b)$ to $(a)$ is higher in effusion than in plasma. Since neoplastic effusions are removed in liter quantities from affected patients, and contain high concentrations of orosomucoid with abnormal carbohydrate composition, these fluids will provide a useful source for further investigation of the cancer-related alteration in the glycoprotein's structure.

Because orosomucoid preparations isolated from neoplastic effusions differ from normal in their carbohydrate content, we have concluded that these fluids contain orosomucoid with abnormal carbohydrate side chains. Alternative explanations could be: $(a)$ orosomu-

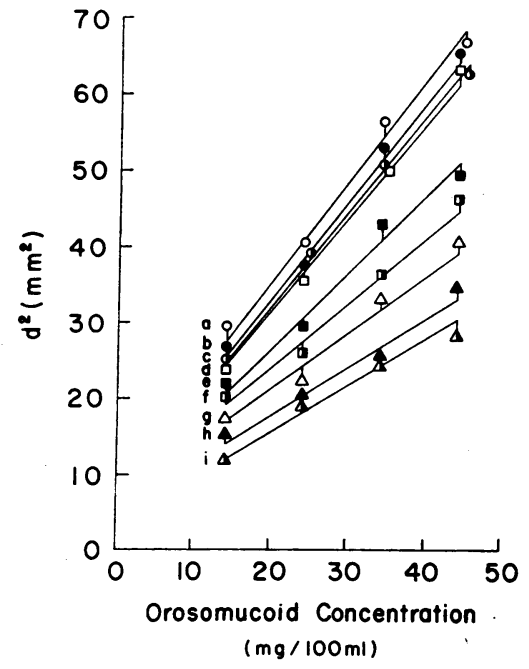

Figure 4 Relation between concentration of orosomucoid and (diameter) ${ }^{2}$ of precipitin ring in radial immunodiffusion against rabbit antiserum to normal human plasma orosomucoid. Each point shows av $\pm \mathrm{SE}$ of four measurements. The nine orosomucoid preparations were derived from the following sources: $a$. normal human plasma; $b$. effusion caused by cirrhosis (case 3 ) ; $c$. effusion caused by cirrhosis (case 4$) ; d$. effusion caused by heart failure (case $17)$; $e$. effusion caused by carcinoma of the lung (case 24); $f$. effusion caused by lymphoma (case 36 ); $g$. effusion caused by carcinoma of the ovary (case 60 ) ; $h$. effusion caused by carcinoma of the breast (case 50 ); $i$. effusion caused by carcinoma of the pancreas (case 75). $P$ value was calculated for difference in slope between line " $a$ " and each other line (20). $P$ was $>0.05$ for $b, c, d, e$, and $f$. For $g, h$, and $i, P$ was $<0.05,<0.02$, and $<0.02$, respectively. 
TABLE II

Carbohydrate Content of Orosomucoid Preparations from Normal Human Plasma and from 26 Effusions

\begin{tabular}{lcccc}
\hline \multicolumn{1}{c}{ Source } & Vield & Sialic acid & Hexose & Hexosamine \\
\hline & $m g / 100 m l$ & & $g / 100$ g orosomucoid & \\
Normal human plasma & $63 \pm 10^{*}$ & $12.4 \pm 0.7^{*}$ & $14.9 \pm 0.8^{*}$ & $15.0 \pm 0.7^{*}$ \\
Case 3, cirrhosis & 15 & 13.3 & 14.5 & 14.8 \\
Case 4, cirrhosis & 17 & 11.8 & 13.9 & 15.1 \\
Case 5, cirrhosis & 28 & 12.6 & 16.2 & 15.3 \\
Case 6, cirrhosis & 12 & 13.4 & 14.7 & 16.2 \\
Case 17, heart failure & 34 & 11.9 & 16.3 & 14.4 \\
Case 18; heart failure & 29 & 13.6 & 14.7 & 16.3 \\
Case 19, heart failure & 38 & 12.2 & 14.3 & 15.7 \\
Case 20, heart failure & 52 & 12.8 & 13.9 & 14.0 \\
Case 24, carcinoma of the lung & 116 & 8.3 & 12.4 & 14.8 \\
Case 25, carcinoma of the lung & 130 & 7.2 & 10.3 & 18.0 \\
Case 36, lymphoma & 150 & 10.4 & 14.9 & 17.8 \\
Case 38, lymphoma & 86 & 12.6 & 15.2 & 14.3 \\
Case 40, lymphoma & 92 & 11.1 & 10.7 & 13.2 \\
Case 45, carcinoma of the breast & 131 & 7.3 & 8.5 & 13.8 \\
Case 50, carcinoma of the breast & 210 & 8.0 & 9.3 & 15.5 \\
Case 57, carcinoma of the breast & 190 & 8.5 & 12.9 & 18.6 \\
Case 60, carcinoma of the ovary & 87 & 6.3 & 15.4 & 19.0 \\
Case 61, carcinoma of the ovary & 167 & 10.3 & 13.9 & 14.9 \\
Case 74, carcinoma of the pancreas & 140 & 12.7 & 13.6 & 14.9 \\
Case 75, carcinoma of the pancreas & 119 & 8.0 & 9.9 & 16.1 \\
Case 76, carcinoma of the pancreas & 89 & 9.4 & 11.7 & 12.0 \\
Case 77, carcinoma of the pancreas & 175 & 11.7 & 14.8 & 14.0 \\
Case 94, tuberculosis & 62 & 11.9 & 15.0 & 14.9 \\
Case 97, lupus erythematosus & 50 & 12.7 & 13.1 & 16.3 \\
Case 100, rheumatoid arthritis & 74 & 11.5 & 14.2 & 15.0 \\
Case 102, idiopathic pleuropericarditis & 40 & 11.8 & 13.5 & 14.6 \\
& & & & \\
\hline
\end{tabular}

*Av $\pm \mathrm{SD}, n=10$.

coid was chemically altered during isolation; $(b)$ orosomucoid preparations contained non-orosomucoid contaminants. Normal carbohydrate composition of orosomucoids isolated in same way from nonneoplastic effusions (Table II) makes (a) unlikely. Normal amino acid composition of neoplastic orosomucoid preparations, and failure of electrophoretic and immunologic tests to detect contaminants in these preparations (Figs. 2 and 3 ), militate against explanation $(b)$.

Mobility of a protein in acrylamide gel electrophoresis is determined by electric charge and molecular size. At $\mathrm{pH} 8.9$ in $7.5 \%$ acrylamide gel, normal orosomucoid migrates nearly as rapidly as the marker dye or buffer front (Fig. 2). Subnormal carbohydrate content could influence mobility in two ways: reduced complement of negatively charged sialic acid residues will tend to retard migration towards anode, while decreased molecular size will accelerate this movement. In fact, orosomucoids of differing carbohydrate content (Table II) migrated at closely similar rates (Fig. 2). Possibly, under different conditions of gel concentration and $\mathrm{pH}$, whereby normal orosomucoid is retarded to a greater degree with respect to buffer front, differences in mobility correlated with sialic acid content and molecular weight may be demonstrable. Thus, acrylamide gel electrophoresis at $\mathrm{pH} 2.7$, but not at 8.9 , showed nonidentical patterns for plasma orosomucoids with differing carbohydrate composition (2).

Concentration of orosomucoid, a significant diagnostic feature in examination of effusions (Appendix), can be rapidly measured by radial immunodiffusion. But the structural abnormality of orosomucoid in most malignant effusions reduces its reactivity with antiserum to normal human plasma orosomucoid (Fig. 4). Therefore values for orosomucoid in these fluids measured by radial immunodiffusion (Table I), with normal human plasma orosomucoid as standard, are falsely low by $10-40 \%$. The extent of this error can be estimated by testing the effusion in radial immunodiffusion at several concentrations, and comparing the slope of the line relating concentration to the square of the diameter of the precipitate area with that of the standard glycoprotein (Fig. 4). 
The characteristic feature of malignant effusions in gel filtration is enlargement of peak $b$ (Fig. 1). Only about $20 \%$ of this increment stems from orosomucoid; the nature of the remainder is unknown. Accumulation of peak $b$ materials may be of clinical significance because one mass unit of this material ( $\mathrm{mol}$ wt $30,000-50,000$ ) possesses 2-3 times more colloid osmotic activity than a mass unit of plasma proteins (av mol wt about 100,000). In neoplastic effusions, the area under peak $b$ ranged from $\frac{1}{8}$ to $\frac{1}{2}$ that under peak $a$ (Fig. 1 ). If mass is proportional to area, the colloid osmotic activity of a unit weight of protein in neoplastic effusions is 50 $100 \%$ greater than that in benign effusions. Such abnormally high osmotic activity of proteins in neoplastic effusions will accelerate entry of $\mathrm{H}_{2} \mathrm{O}$ into the involved synovial cavity. Thus, accumulation of peak $b$ material may play a role in the formation of malignant effusions and in their tendency to reaccumulate rapidly after paracentesis.

Carbohydrate-containing proteins and lipids are prominent constituents of cellular plasma membranes and glycocalyces $(14,15)$. "Ektobiologic" properties of cells such as contact inhibition, adhesiveness, and "homing" capacity may be determined in part by these carbohydrate-rich molecules (14-16). Glycolipids in some neoplastic cells are deficient in carbohydrates, perhaps because of abnormality in activity of glycosyl transferases $(17,18)$. Enzymes of this type also participate in biosynthesis of glycoproteins (13-15). Circulating glycoproteins, normally produced largely in the liver, may in tumor-bearing animals also be secreted into body fluids by neoplastic cells $(8,9,19)$. These considerations suggest that the accumulation of orosomucoid with abnormal carbohydrate side chains in body fluids of patients with disseminated cancer (ref. 2 and present study) may be related to invasive properties of neoplastic cells in the patients under consideration.

\section{APPENDIX}

The utility of the various concentrations or indices for characterizing neoplastic and nonneoplastic noninflammatory effusions can be compared by the multivariate statistical techniques of discriminant analysis (21). Briefly, discriminant analysis permits the classification of individuals (effusions) into two or more groups (in this case two groups, neoplastic and nonneoplastic noninflammatory) in terms of one or more variables (total protein, albumin, etc.). The purpose of such an analysis is to find a discriminant function: that is, a linear combination of the variables that will maximally differentiate between the two types of effusion. For example, consider the following four variables measured in the units of Table I: $x_{1}=$ albumin, $x_{s}=\alpha_{2}$-globulin, $x_{s}=\gamma$-globulin, and $x_{4}=$ orosomucoid concentration. The statistical
TABLE III

Classification of Effusions by a Four-Term Linear Discriminant

\begin{tabular}{lcc}
\hline & \multicolumn{2}{c}{ Diagnostic classification } \\
\cline { 2 - 3 } Discriminant classification & Neoplastic & Benign \\
\hline $\begin{array}{c}\text { Neoplastic } \\
\text { Nonneoplastic } \\
\text { noninflammatory }\end{array}$ & 50 & 0 \\
Total & 6 & 22 \\
\hline
\end{tabular}

problem is to find the linear combination, $a_{1} x_{1}+a_{2} x_{2}+$ $a_{s} x_{3}+a_{4} x_{4}$, which produces the "best" discriminant. The values for $a_{1}, a_{2}, a_{3}$, and $a_{4}$, are estimated from the data; substituting the value of the four original variables $\left(x_{1}, x_{2}, x_{3}\right.$, and $\left.x_{4}\right)$ for each effusion into this equation then produces a new variable that is a linear combination of the originals. The difference between the average values of this new variable for the nonneoplastic noninflammatory and neoplastic groups will be a maximum, in the sense that no other linear combination of these four variables can produce better separation or discrimination of the two groups. Furthermore, a particular value of the discriminant function can be used as a cut-off point for classifying subsequent effusions. That is, new measurements on an unclassified effusion can be substituted into the discriminant equation and, depending on whether the resulting value is less or greater than the specified cut-off point, the effusion is classified as nonneoplastic noninflammatory or neoplastic. The probability of correct classification may also be computed. All computational aspects of the discriminant analysis of the present data were performed with the aid of the UCLA Biomedical Computer Program BMDO7M (22).

For the present data, the linear discriminant for the four variables mentioned above is $0.65 x_{1}+7.43 x_{8}-$ $5.00 x_{s}+0.06 x_{4}$. The correctness of classification of effusions by this equation can be conveniently summarized in Table III. In this case, 50 of the 56 neoplastic effusions were correctly classified by the linear discriminant; all 22 of the nonneoplastic noninflammatory effusions were correctly classified. (Note: Only 78 patients were used in this analysis; two patients were excluded because of missing observations on one of the variables.) In fact, among the seven variables (total protein, albumin, $\alpha_{1}, \alpha_{2}, \beta$, and $\gamma$-globulins, and orosomucoid) that could be included in a discriminant analysis, the four (albumin, $\alpha_{\boldsymbol{x}}$, and $\gamma$-globulins, and orosomucoid) used in the above example provide the best discriminant function based on a stepwise procedure (22). No further improvement in discrimination can be achieved by adding $\alpha_{1}$ and $\beta$-globulins or total protein to the discriminant analysis. 
TABLE IV

Classification of Effusions as Benign, Noninflammatory, or Neoplastic by Discriminant Analysis on Individual Variables, Selected Ratios, and a Linear Combination of Variables

\begin{tabular}{|c|c|c|c|c|c|c|c|c|c|c|c|c|}
\hline \multirow[b]{2}{*}{ Diagnostic classification } & \multirow[b]{2}{*}{ Discriminant classification } & \multicolumn{11}{|c|}{ Variables } \\
\hline & & 1 & 2 & 3 & 4 & 5 & 6 & 7 & 8 & 9 & 10 & 11 \\
\hline Neoplastic & Neoplastic & 32 & 31 & 39 & 41 & 27 & 39 & 41 & 47 & 48 & 41 & 50 \\
\hline Neoplastic & Benign noninflammatory & 24 & 25 & 17 & 15 & 29 & 17 & 15 & 9 & 8 & 15 & 6 \\
\hline Benign noninflammatory & Benign noninflammatory & 15 & 18 & 13 & 16 & 15 & 8 & 21 & 14 & 22 & 20 & 22 \\
\hline \multirow[t]{2}{*}{ Benign noninflammatory } & Neoplastic & 7 & -4 & 9 & 6 & 7 & 14 & 1 & 8 & 0 & 2 & 0 \\
\hline & Total & 78 & 78 & 78 & 78 & 78 & 78 & 78 & 78 & 78 & 78 & 78 \\
\hline
\end{tabular}

Variables are identified as follows: 1 , Total protein; 2, Albumin; $3, \alpha_{1}$-globulin; 4, $\alpha_{2}$-globulin; $5, \beta$-globulin; 6, $\gamma$-globulin; $7,\left(\alpha_{1}+\alpha_{2}\right) / \gamma ; 8, \gamma /$ total protein ; 9 , orosomucoid; 10 , orosomucoid/total protein; 11 , the four-term linear discriminant 0.65 (albumin) $+7.43\left(\alpha_{2}\right.$-globulin $)-5.00(\gamma$-globulin $)+0.06$ (orosomucoid).

The ability of individual variables, or of selected ratios of variables, to discriminate between the two types of effusion can also be examined in the above fashion. In such cases the statistical problem is simplified, in that classification is based on the means of the single variable for each group. A particular observation is classified according to its "closeness" to one or the other group mean after appropriate standardization of the scale of measurement. Each of the seven individual variables and, in addition, the ratios $\left(\alpha_{1}+\alpha_{2}\right) / \gamma$-globulin, $\gamma$-globulin/total protein, and orosomucoid/total protein were examined in this fashion. The correctness of classification for each of these 10 possibilities is summarized in Table IV.

Clearly, variable 9, orosomucoid concentration, is the best single variable among the first 10 possibilities for classifying effusions into nonneoplastic noninflammatory and neoplastic categories; 48 of the 56 neoplastic effusions and all 22 nonneoplastic noninflammatory effusions were correctly classified by this variable alone. The linear discriminant with four variables (column 11) did only slightly better. The ratio of $\left(\alpha_{1}+\alpha_{2}\right) / \gamma$-globulin (variable 7) correctly classified 49 of 56 neoplastic effusions and 21 of 22 benign noninflammatory effusions. In decreasing order of discriminatory value, the ratios $\gamma$-globulin/total protein and orosomucoid/total protein were next, with each correctly classifying 61 of the 78 effusions, followed by $\alpha_{2}$-globulin alone ( 57 of 78 correct) and ending with $\beta$-globulin alone (42 of 78 correct). The other variables or ratios were intermediate in their discriminatory value.

Hence, from the perspective of discriminant analysis, orosomucoid concentration stands out as a particularly useful measurement for discriminating between neoplastic and benign noninflammatory effusions. Very little improvement in discrimination was achieved by adding other variables to a discriminant function.

\section{ACKNOWLEDGMENTS}

This investigation was supported by U. S. Public Health Service grants CA 12646-02 and RR-39.

\section{REFERENCES}

1. Winzler, R. J. Determination of serum glycoprotein. 1955. Methods Biochem. Anal. 2: 279-311.

2. Rudman, D., P. E. Treadwell, W. R. Vogler, C. H. Howard, and B. Hollins. 1972. Abnormal orosomucoid in the plasma of patients with neoplastic disease. Cancer Res. 32: 1951-1959.

3. Gornal, A. G., C. J. Bardawell, and M. M. David. 1949. Determination of serum proteins by means of the biuret reaction. J. Biol. Chem. $177:$ 751-766.

4. Grunbaum, B. W., M. F. Lyons, N. V. Caroll, and J. Zec. 1963. Quantitative analysis of normal human serum proteins on permanently transparentized cellulose acetate membranes. Microchem. J. $7: 54-56$.

5. Rudman, D., A. Del Rio, S. Akgun, and E. Frumin. 1969. Novel proteins and peptides in the urine of patients with advanced neoplastic disease. $\mathrm{Am}$. J. Med. 46: 174-187.

6. Mancini, G., A. O. Carbonara, and J. F. Heremans. 1965. Immunochemical quantitation of antigens by single radial immunodiffusion. Immunochemistry. 2: 235-254.

7. Andrews, P. 1964. Estimation of molecular weights of proteins by sephadex gel-filtration. Biochem. J. 91: 222-233.

8. Winzler, R. J. Determination of serum glycoproteins. In Biochemistry of Glycoproteins and Related Substances. E. Rossi and E. Stoll, editors. Fourth International Conference on Cystic Fibrosis of the Pancreas, Part II. S. Karger AG, Basel. 226-243.

9. MacBeth, R. A., and J. G. Bekesi. 1964. Effect of transplantable tumors on the seromucoid fraction of rat serum. Cancer Res. 24: 2044-2048.

10. Rovestad, R. A., L. G. Bartholemew, J. C. Cain, B. F. McKenzie, and E. H. Soule. 1958. Ascites. I. The value of examination of ascites fluids and blood for lipids and for proteins by electrophoresis. Gastroenterology. 34: 436-450.

11. Spak, I. 1960. On the clinical value of chemical analysis of ascites. Acta Chir. Scand. Suppl. 261: 1-128.

12. Schmid, K., J. P. Binnette, S. Kamiyama, V. Pfister, and S. Takahashi. 1962. Studies of the structure of 
$\alpha_{1}$-acid glycoprotein and the partial resolution and characterization of its variants. Biochemistry. 1: 959-966.

13. Spiro, R. G. 1970. Glycoproteins. Ann. Rev. Biochem. 39: 599-638.

14. Cook, G. M. W. 1968. Glycoproteins in membranes. Biol. Rev. (Camb.). 43: 363-391.

15. Winzler, R. J. 1970. Carbohydrates in cell surfaces. Int. Rev. Cytol. 29 : 77-125.

16. Kalckar, H. M. 1965. Galactose metabolism and cell "sociology". Science (Wash. D. C.). 150: 305-313.

17. Hakomori, S., and W. T. Murakami. 1968. Glycolipids of hamster fibroblasts and derived malignant-transformed cell lines. Proc. Natl. Acad. Sci. U. S. A. 59: 254-261.

18. Hakomori, S., C. Teather, and H. Andrews. 1968. Organizational difference in cell surface "hematoside" in normal and virally transformed cells. Biochem. Biophys. Res. Comm. 33: 563-568.

19. Eveleigh, J. M. 1972. Glycoproteins excreted by SV40transformed cells. In Embryonic and Fetal Antigens in Cancer. 2nd volume. National Technical Information Service, U. S. Dept. Commerce, Springfield, Va. Conf. 720208. 133-137.

20. Goldstein, A. 1964. Biostatistics. The Macmillan Company, New York. 144.

21. Morrison, D. S. Multivariate Statistical Methods. 1967. McGraw-Hill Book Company, New York. 130.

22. Dixon, W. J. 1967. University of California Publications in Automatic Computation No. 2, BMD Biomedical Computer Program. University of California Press, Berkeley, Calif. 185-195. 